\title{
GLOBAL SCIENCE LIBRARY
}

\section{Clinical characteristics of ectopic pancreas in digestive system}

\author{
Jiangang Sun ${ }^{1}$, Yang Shi ${ }^{2}$, Quancheng $\mathrm{Kan}^{2}$ and Yong shun $\mathrm{Ga}^{2 *}$ \\ ${ }^{1}$ Departments of Gastrointestinal Surgery, The First Affiliated Hospital of Zhengzhou University, China \\ ${ }^{2}$ Departmnet of GI Medicine, The First Affiliated Hospital of Zhengzhou University, China
}

\begin{abstract}
Aim: PThis study aims to investigate the clinical features and therapeutic strategy of ectopic pancreas (EP) in the digestive system. Methods: We performed a retrospective analysis of 191 pathologically, from January 2012 to December 2017, verified cases of EP over the past five years from the first affiliated hospital of Zhengzhou University to standardize the therapeutic regimen, which could provide better guidance for the future patients. According to the treatment methods the patients were divided into three groups: conservative treatment (Group A), endoscopic treatment (Group B), and surgery operation (Group C). They were performed to summarize their clinical characteristics and followup study on therapeutic effects.

Results: The patients did not show significant symptoms (or physical examination) in the clinical manifestations, which were obviously symptom (81.15\%, $P<0.001)$. Most of patients conduct endoscopic examination $(91.62 \%, P<0.001)$ and the size of tumor in $B$ and $C$ groups was significantly larger than that in group $A(P<0.000)$. Each patient was followed up for six months, all of the patients in these three groups showed no significant postoperative differences of gastrointestinal symptoms $(P=0.134)$ or mental stress $(P=0.357)$. However, the number of patients with awareness of disease in group $B$ and group $C$ was significantly higher than that in group $A(P=0.001)$.

Conclusions: In this study, patients with EP show no characteristic clinical manifestations and endoscopic examination has a good diagnostic effect. Endoscopic therapy should be the first choice of treatment except for a large mass that must be treated surgically.
\end{abstract}

Keywords: ectopic pancreas, surgery, endoscopic, therapy

\section{Introduction}

Ectopic pancreas (EP) is characterized by growth outside the in-situ orthotopic pancreas without anatomic and vascular connections, which was first reported in the 18th century [1]. The pathogenesis of EP presumably attributes to the incorrect migration of ventral or dorsal pancreatic buds during embryonic development [2]. Previous studies reported that EP may locate within or outside the alimentary tract, including the most common sites stomach, duodenum, proximal jejunum, and some rare locations, such as liver, gallbladder, spleen, and mesentery [3-5]. Epigastric discomfort is the most common clinical symptoms of EP, while the specific symptoms are often vague. Usually the symptoms could deteriorate when accompanied by inflammation, bleeding, obstruction, and pseudocyst formation [6,7]. Preoperative diagnosis of EP remains challenging because the imageological examination (computerized tomography, endoscopy, and ultrasonography) is nonspecific and biopsy is rarely available [8,9]. The classic appearance of this congenital anomaly is intramural mass with central umbilication [10]. However, when the umbilication is abnormal, this feature is difficult to distinguish from other lesions, including gastrointestinal stromal tumor, adenomatous polyp, and leiomyoma [11].

Nowadays, according to the size, location, and complications of the lesion, the main treatment options are open surgery, laparoscopic surgery, endoscopic resection, and conservative treatment [12-14]. Because the worldwide EP incidence is relatively rare disease, mainly attributing to surgery or autopsy, routine researches provided inconclusive information based on a limited number of cases $[15,16]$. Therefore, EP is defined as a rare disease and the comprehensive analysis between clinical characteristics, treatment, and prognosis is deficient. Herein, we performed a retrospective study of 191 pathologically verified EP cases over the past five years at the first affiliated hospital of Zhengzhou University to standardize therapeutic regimen, which could provide instructional treatment recommendations to the future patients.

\section{Patients and methods}

Heterotopic pancreas patients in the digestive system collected from January 2012 to December 2017 at the First Affiliated Hospital of Zhengzhou University were conducted in a retrospective analysis. The clinical characteristics and follow-up study on the therapeutic effect of these patients (human ethics clearance number: 2018-KY-05) were also summarized. Inclusion criteria: Pathological examination for ectopic pancreas (endoscopic biopsy or post-surgical specimen examination in Figure 1. Pathological diagnosis criteria are shown in Figure 2; signed informed consent and accepted follow-up survey. Exclusion criteria: Follow-up failure.

A total of 198 patients were recruited, while five patients lost contact after six months and 2 cases with telephone contact were refused hospital follow-up, and the remaining 191 patients were included in the study.

There were three main treatment methods: conservative treatment (Group A), Endoscopy examination was performed 

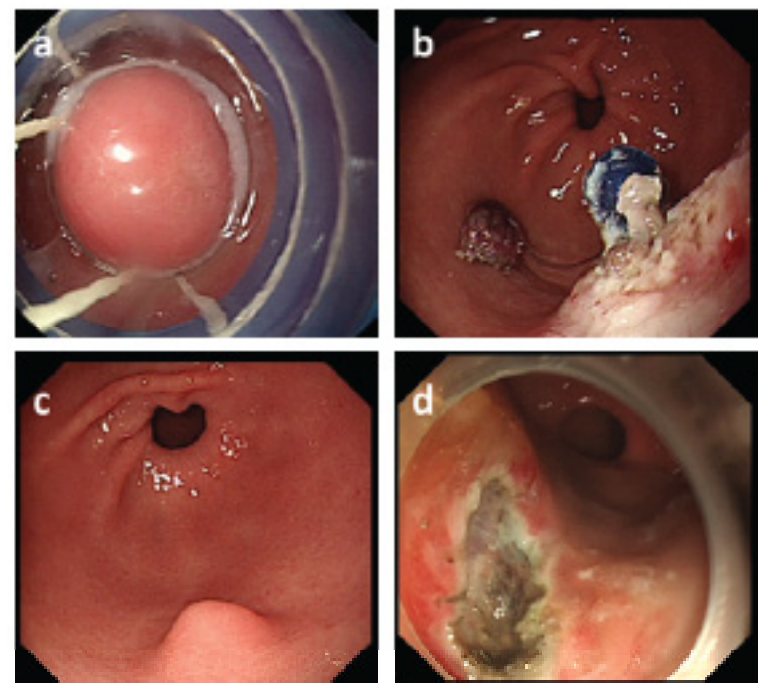

Figure 1. Representative photographs of the process of endoscopic treatment. A. Endoscopic ligation: surround the tumour; B. Excision of tumor; C. ESD: tumor manifestation under microscope; D. Post excision wound
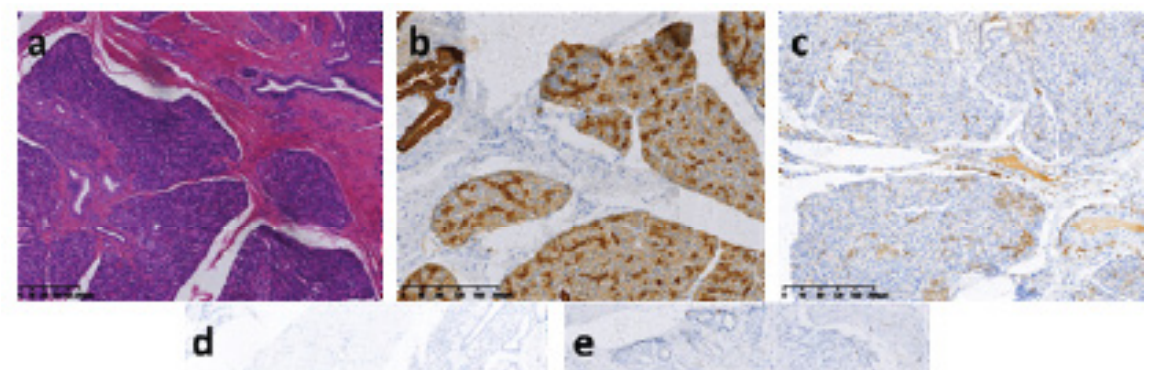

d
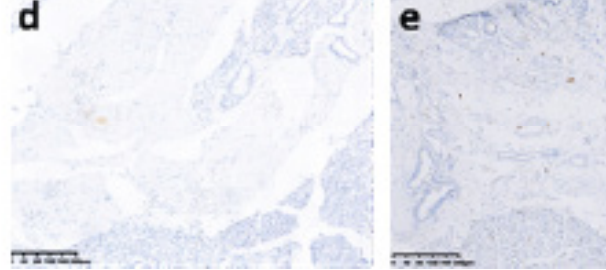

Figure 2. Representative photographs of pathological diagnosis. (A) H\&E staining, $\times 100$, nodular masses in the muscular layer, including a well differentiated fat, blood vessels and ducts; The expressions of (B) CK19, epithelial tissue (+), (C) CD56, blood vessel (+); (D) CEA, adipose tissue (-); (F) Ki-67, (cell proliferation index $<10 \%)$ were detected by immunohistochemistry, and the representative photographs were shown (100×). These features indicate that the organization has no atypia, it is the change of EP.

every 6 months to observe whether there was any change. If there was no obvious change in EP, no special treatment was needed. If the progressive enlargement exceeds $1 \mathrm{~cm}$, endoscopic or surgical resection was recommended. Endoscopic treatment (Group B), endoscopy revealed polyp $\leq 2 \mathrm{~cm}$ and located in the digestive tract. Surgery (Group C), possible surgical resection after endoscopy and CT examination. Endoscopic treatment included endoscopic ligation (Figure 1A and 1B), endoscopic submucous dissection (ESD) [17] (Figure 1C and 1D) with LED light source having a wave length between $580 \sim 595 \mathrm{~nm}$ and a power of $200 \mathrm{~W}$. And the final diagnosis of ectopic pancreas is pathological diagnosis (Figure 2A-E).

The main observation indicators included the gender, sex, age, tumor growth site, clinical presentation, endoscopic examination, misdiagnosis rate, and tumor size (diameter). The main clinical manifestations were abdominal pain, abdominal distention, no special clinical manifestation or physical examination, gastrointestinal bleeding, intestinal obstruction, intussusception, and other symptoms. The growth site of the tumor was mainly located in the stomach, duodenum, jejunum, ileum, and other area such as the gallbladder and liver.

The patients conducting the above regimen were continued to follow up for 6 months. The recurrence, complications, symptom of digestive tract, mental stress (Quality of life and depression [18]), and recognition of the disease were recorded during followup.

All the collected data were statistical analyzed using SPSS 22.0 software (IBM, New York, Armonk, USA). Bilateral test was used, and $\mathrm{P}<0.05$ was considered statistically significant. Count data of age and tumor size were expressed as $\mathrm{x} \pm \mathrm{s}$, univariate anova was used for multi-group comparison, and LSD test was used for intergroup comparison. Categorical data such as gender, lesion location and clinical manifestations were examined by $X$ test. Univariate anova was used for multigroup comparison and P-value correction was used for pairwise comparison. 

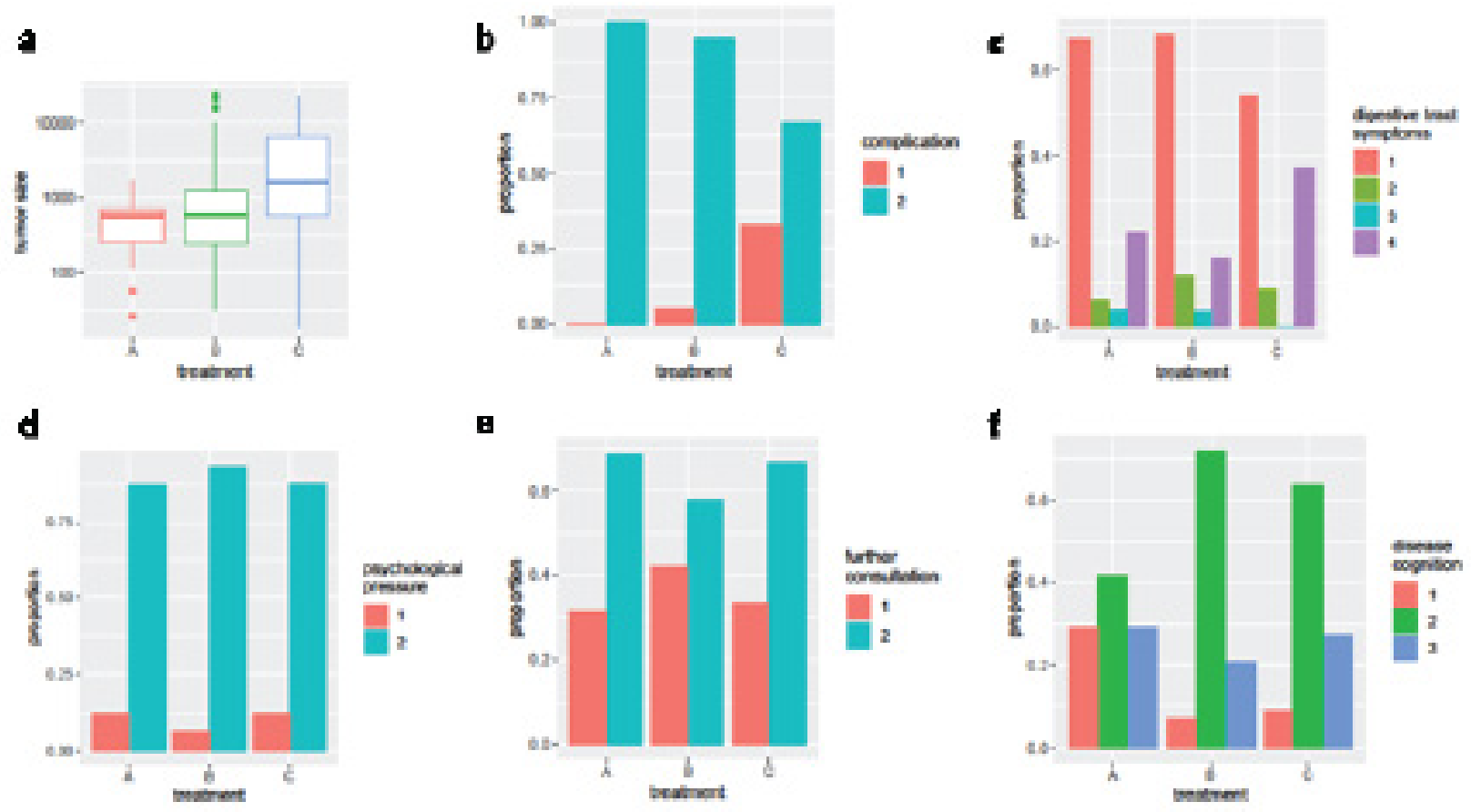

Figure 3. Grouping and characteristics of EP. A was conservative treatment group, B was endoscopic treatment group, and C was surgery operation Group C. $A$. The mean tumor size the three groups was $1.2 \pm 1.59 \mathrm{~cm}$. The tumor size of group $C$ was significantly larger than that of group $A(P<0.001)$ and group $B(P<0.001)$, and EP for endoscopic resection was generally less than $2 \mathrm{~cm} . B .1$, yes, 2, no. Surgical complications were significantly higher than endoscopic $(P<0.001)$ and conservative treatment $(P<0.001)$, and endoscopic treatment was significantly higher than conservative treatment $(P<0.001)$. Surgical treatment could result in a relatively high number of complications. C. 1, no symptoms, 2, acid reflux and heartburn, 3, nausea and vomiting, 4, bloating, abdominal pain and diarrhea. The number of asymptomatic surgical treatment group (66.7\%) was relatively small, but did not differ statistically from other groups. And there was no significant difference between the symptoms. This may be one of the main reasons for the high rate of EP misdiagnosis. D. 1, yes, 2 , no. Although there was no significant difference in mental stress between the groups, overall mental stress occurred in $8.9 \%$ of the patients. E. 1 , yes, 2 , no. As can be seen from the rate of return visit, although there was no significant difference among the groups, the overall rate of return visit was low (37.70\%), which means that people did not attach much importance to it. F. 1, no cognizance, 2, comprehend, 3, fully understand. The proportion of unknown patients in the conservative treatment group (29.2\%) was significantly higher than that in the endoscopic treatment group (7.3\%) and the surgical group (9.1\%). With understanding, group B and C were significantly higher than group A. When fully understood, there were no statistically significant differences between the groups.

\section{Results}

The 191 patients included 104 males and 87 females, aged 3 days to 79 years (mean, 41.99 years). Among them, group $C$ has 3 patients whose age is not more than 6 years old. There was no significant difference in age and sex among the three groups. There was no significant difference in the location between group $\mathrm{A}$ and group $\mathrm{B}(\mathrm{P}=0.176)$, but Group $\mathrm{C}$ was significantly different from the other two groups $(\mathrm{P}<0.001)$. Clinically, the number of patients with no significant symptoms (or physical examination) was found to be significantly higher $(\mathrm{P}<0.001)$. Group $\mathrm{C}$ was significantly different from group $\mathrm{A}(\mathrm{P}=0.000)$ and group $\mathrm{B}(\mathrm{P}=0.000)$, and the results also showed that there were 15 cases having other clinical manifestations in group $\mathrm{C}$, while 2 cases in group A and $\mathrm{B}$. The endoscopic examination results showed that the number of compatible cases was significantly higher $(\mathrm{P}<0.001)$, except for 5 cases were not examined and 11 cases could not be diagnosed definitively. The results showed that there were 10 patients in group $\mathrm{C}$ without definite diagnosis, while only 1 case in group $\mathrm{A}$ and $\mathrm{B}$, which indicated that Group $\mathrm{C}$ was significantly different from group $\mathrm{A}(\mathrm{P}<0.000)$ and group $\mathrm{B}(\mathrm{P}<0.001)$. The difference in misdiagnosis rate between the three groups were non-significant
$(\mathrm{P}=0.427)$, and the total misdiagnosis rate was $91.10 \%$. The size of tumor in $\mathrm{B}$ and $\mathrm{C}$ groups was significantly larger than that in group $\mathrm{A}(\mathrm{P}<0.001$, Figure $1 \mathrm{~A})$. The other results were listed in Table 1.

In the 6 months of follow-up, 3 patients accepted endoscopic resection, according to conservative management standards (Group A). 9 patients developed recurrent (Group B $=6$, Group C $=3$ ). 3 patients developed malignant tumors (Group $B=2$, Group $\mathrm{C}=1$ ). There was no significant difference in relapse probability among the three groups $(\mathrm{P}=0.752)$. The patients in group $\mathrm{A}$ were treated conservatively so that group A did not participate in complication-related comparisons, while the complications of group $\mathrm{C}$ were significantly higher than those of group $\mathrm{B}(\mathrm{P}<$ 0.001 , Figure 1B). After treatment, both the digestive symptoms ( $\mathrm{P}$ $=0.134$, Figure $1 \mathrm{C})$, the mental stress $(P=0.357$, Figure $1 \mathrm{D})$ and further consultation $(\mathrm{P}=0.384$, Figure $1 \mathrm{E})$ in three groups did not show significantly difference. However, the awareness of disease in group $\mathrm{B}$ and group $\mathrm{C}$ was significantly higher than that in group A $(P=0.001$, Figure $1 F)$. The rest of the results were shown in Table 2. Comparisons between the three groups are illustrated in detail in Figure 3. 


\begin{tabular}{|c|c|c|c|c|c|c|c|c|c|c|c|c|c|}
\hline \multirow[b]{2}{*}{ Characteristic } & \multicolumn{4}{|c|}{ Group A $(n=48)$} & \multicolumn{4}{|c|}{ Group B $(n=110$} & \multicolumn{4}{|c|}{ Group C $(n=33)$} & \multirow[b]{2}{*}{$\mathbf{P}$} \\
\hline & No. & $\begin{array}{c}\text { Rate } \\
(\%)\end{array}$ & Mean & SD & No. & $\begin{array}{c}\text { Rate } \\
(\%)\end{array}$ & Mean & SD & No. & $\begin{array}{c}\text { Rate } \\
(\%)\end{array}$ & Mean & SD & \\
\hline $\begin{array}{l}\text { Sex } \\
\text { Male } \\
\text { Female }\end{array}$ & $\begin{array}{l}27 \\
21\end{array}$ & $\begin{array}{l}56.3 \\
43.7\end{array}$ & & & $\begin{array}{l}59 \\
51\end{array}$ & $\begin{array}{l}53.6 \\
46.5\end{array}$ & & & $\begin{array}{l}18 \\
15\end{array}$ & $\begin{array}{l}54.5 \\
45.5\end{array}$ & & & 0.955 \\
\hline $\begin{array}{l}\text { Age, years } \\
\leq 6 \mathrm{y}\end{array}$ & 0 & & 45.2 & 13.0 & 0 & & 41.1 & 12.9 & 3 & & 40.2 & 21.4 & 0.207 \\
\hline $\begin{array}{l}\text { Position } \\
\text { Stomach } \\
\text { Duodenum } \\
\text { Jejunum \& ileum } \\
\text { Other }^{\mathrm{a}}\end{array}$ & $\begin{array}{c}40 \\
8 \\
0 \\
0\end{array}$ & $\begin{array}{c}83.3 \\
16.7 \\
0.0 \\
0.0\end{array}$ & & & $\begin{array}{c}106 \\
3 \\
1 \\
0\end{array}$ & $\begin{array}{c}96.4 \\
2.7 \\
0.9 \\
0.0\end{array}$ & & & $\begin{array}{c}21 \\
3 \\
6 \\
3\end{array}$ & $\begin{array}{c}63.6 \\
9.1 \\
18.2 \\
9.1\end{array}$ & & & $<0.001$ \\
\hline $\begin{array}{l}\text { Clinical symptoms } \\
\text { No symptoms } \\
\text { Stomachache } \\
\text { Abdominal distention } \\
\text { Otherb }\end{array}$ & $\begin{array}{c}38 \\
6 \\
3 \\
1\end{array}$ & $\begin{array}{c}79.2 \\
12.4 \\
6.3 \\
2.1\end{array}$ & & & $\begin{array}{c}102 \\
6 \\
1 \\
1\end{array}$ & $\begin{array}{c}92.7 \\
5.5 \\
0.9 \\
0.9\end{array}$ & & & $\begin{array}{c}15 \\
3 \\
0 \\
15\end{array}$ & $\begin{array}{c}45.5 \\
9.0 \\
0 \\
45.5\end{array}$ & & & $<0.001$ \\
\hline $\begin{array}{l}\text { Endoscopy } \\
\text { Definite diagnosis } \\
\text { Not checked } \\
\text { Unclear diagnosis }\end{array}$ & $\begin{array}{c}48 \\
0 \\
0\end{array}$ & $\begin{array}{c}100.0 \\
0.0 \\
0.0\end{array}$ & & & $\begin{array}{c}109 \\
0 \\
1\end{array}$ & $\begin{array}{c}99.1 \\
0.0 \\
0.9\end{array}$ & & & $\begin{array}{c}18 \\
5 \\
10\end{array}$ & $\begin{array}{c}54.5 \\
15.2 \\
2.6\end{array}$ & & & $<0.001$ \\
\hline $\begin{array}{l}\text { Misdiagnosis } \\
\text { Yes } \\
\text { No }\end{array}$ & $\begin{array}{c}43 \\
5\end{array}$ & $\begin{array}{l}89.6 \\
10.4\end{array}$ & & & $\begin{array}{l}99 \\
11\end{array}$ & $\begin{array}{l}90.0 \\
10.0\end{array}$ & & & $\begin{array}{c}32 \\
1\end{array}$ & $\begin{array}{c}97.0 \\
3.0\end{array}$ & & & 0.427 \\
\hline Tumor size (cm) & & & 0.51 & 0.43 & & & 0.98 & 1.43 & & & 2.44 & 1.64 & $<0.001$ \\
\hline
\end{tabular}

Table 1. Patient clinical characteristics at baseline A was conservative treatment group, B was endoscopic treatment group, and $C$ was surgery operation Group C. (a) In group C, 1 case was located in the gallbladder and 2 cases were located in the liver. (b) Nausea, vomiting, acid reflux and heartburn. Misdiagnosis, pre-hospital diagnosis. Tumor size, diameter.

\begin{tabular}{|c|c|c|c|c|c|c|c|}
\hline & $\begin{array}{c}\text { Group A } \\
(\mathrm{n}=48)\end{array}$ & & $\begin{array}{c}\text { Group B } \\
(n=110)\end{array}$ & & $\begin{array}{c}\text { Group C } \\
(n=33)\end{array}$ & & \\
\hline $6 \mathrm{M}$ of follow-up & No. & Rate (\%) & No. & Rate (\%) & No. & Rate (\%) & $\mathrm{P}$ \\
\hline $\begin{array}{l}\text { Complication } \\
\text { Yes } \\
\text { No }\end{array}$ & $\begin{array}{c}0 \\
48 \\
\end{array}$ & $\begin{array}{c}0.0 \\
100.0\end{array}$ & $\begin{array}{c}6 \\
104\end{array}$ & $\begin{array}{c}5.5 \\
94.5\end{array}$ & $\begin{array}{l}11 \\
22\end{array}$ & $\begin{array}{l}33.3 \\
66.7\end{array}$ & $<0.001$ \\
\hline $\begin{array}{l}\text { Digestive tract symptoms } \\
\text { Yes } \\
\text { No }\end{array}$ & $\begin{array}{l}14 \\
34\end{array}$ & $\begin{array}{l}29.2 \\
70.8\end{array}$ & $\begin{array}{l}33 \\
77\end{array}$ & $\begin{array}{l}30.0 \\
70.0\end{array}$ & $\begin{array}{l}12 \\
21\end{array}$ & $\begin{array}{l}36.4 \\
63.6\end{array}$ & 0.248 \\
\hline $\begin{array}{l}\text { Psychological pressure } \\
\text { Yes } \\
\text { No }\end{array}$ & $\begin{array}{c}6 \\
42 \\
\end{array}$ & $\begin{array}{l}12.5 \\
87.5\end{array}$ & $\begin{array}{c}7 \\
103\end{array}$ & $\begin{array}{c}6.4 \\
93.6\end{array}$ & $\begin{array}{c}4 \\
29\end{array}$ & $\begin{array}{l}12.1 \\
87.9\end{array}$ & 0.357 \\
\hline $\begin{array}{l}\text { Further consultation } \\
\text { Yes } \\
\text { No }\end{array}$ & $\begin{array}{l}15 \\
33\end{array}$ & $\begin{array}{l}31.3 \\
68.8\end{array}$ & $\begin{array}{l}46 \\
64 \\
\end{array}$ & $\begin{array}{l}41.8 \\
58.2\end{array}$ & $\begin{array}{l}11 \\
22\end{array}$ & $\begin{array}{l}33.3 \\
66.7\end{array}$ & 0.384 \\
\hline $\begin{array}{l}\text { Disease cognition } \\
\text { No cognizance } \\
\text { Comprehend } \\
\text { Fully understand }\end{array}$ & $\begin{array}{l}14 \\
20 \\
14\end{array}$ & $\begin{array}{l}29.2 \\
41.6 \\
29.2\end{array}$ & $\begin{array}{c}8 \\
79 \\
23\end{array}$ & $\begin{array}{c}7.3 \\
71.8 \\
20.9\end{array}$ & $\begin{array}{c}3 \\
21 \\
9\end{array}$ & $\begin{array}{c}9.1 \\
63.6 \\
27.3\end{array}$ & 0.001 \\
\hline
\end{tabular}

Table 2. 6 months of follow-up of patients. A was conservative treatment group, B was endoscopic treatment group, and C was surgery operation Group C. Complications were counted as BC group, mainly including bleeding, infection, deep venous thrombosis of lower extremity, obstruction and leakage. Digestive symptoms include acid reflux, heartburn, nausea, vomiting, bloating, abdominal pain and diarrhea. Psychological pressure includes anxiety, irritability and nervousn 


\section{Discussion}

EP is a submucosal lesion most commonly occurs in the stomach, duodenum, and jejunum [19,20], and it can also be seen in many parts of the body, such as ileum, Meckel's diverticulum, mesentery, etc $[21,22]$. Most researchers conducted retrospective studies through case reports or a small number of cases to get recognition of ectopic pancreas. The clinical features of ectopic pancreas are quite variable, and it is easy to misdiagnose EP as other digestive system diseases. The misdiagnosis rate of EP is so high and the treatment options for EP are also diverse. Therefore, we investigated the 191 cases data of EP in our hospital, and further analyzed their characteristics.

EP may occur at any age, primarily of 40 to 70 years old, with no difference in gender [23,24]. Onset ages of EP in this study ranged from 3 days to 79 years (mean, 41.99 years). It is worth mentioning that the smallest patient in this study was a newborn of 3 days, whose clinical manifestation was intussusception caused by a 2.5 $\mathrm{cm}$ EP mass. This newborn was cured after surgical treatment. This case is good evidence of a congenital disease. And the remaining two children were also treated with surgery. Therefore, for young children, larger EP still requires surgical treatment. About $90 \%$ of EP is located in the upper digestive tract, mainly in the stomach (usually located in the greater curvature of the pylorus within 5 $\mathrm{cm}$ ), duodenum, and jejunum [17]. Rare locations of EP include common bile duct, liver, and so on. Clinical manifestations of EP are often the same as clinical symptoms of upper gastrointestinal tract [25]. In our study, EP in the stomach and duodenum could be treated by conservative treatment or endoscopic treatment. And the clinical manifestations of these sorts of EP were not obvious, which were often found in physical examination. While the clinical manifestations of some EP patients presented as abdominal pain and abdominal distention. However, the clinical symptoms were relatively serious, when the EP grows in intestinal obstruction, intussusception, jaundice, and these sorts usually needed to be treated by surgery.

EP is prone to be confused with other digestive tract diseases and easily misdiagnosed as stromal tumor, gastric malignant tumor, and so on [11]. CT is a good method to diagnose EP, especially when some EP not located in the digestive tract, which is difficult for endoscopic examination. However, CT has no advantage for some small EP. Furthermore, EP occurs most frequently in the stomach and duodenum, which is easily diagnosed by digestive endoscopy. The occupying sites found by endoscopic examination can be directly grabbed and further confirmed by pathological biopsy, which is more effective to diagnose EP.

This study also found that there are great differences in the choice of treatment modalities for different size of EP. Conservative treatment for small EP $(0.51 \pm 0.43 \mathrm{~cm})$ can achieve good curative effect. Endoscopic and surgical excision are still good choices for EP patients with larger and serious clinical complications. After 6 months' follow-up for all the patients in this study, we found that postoperative complications in surgical operation were significantly higher than endoscopic treatment. Probably because patients in surgical group often have other diseases, such as malignant tumor, digestive tract obstruction, intussusception, and gastrointestinal bleeding, etc. Because this study is retrospective analysis, then we could only objectively explain these observations. We will continue to look at issues related to ectopic pancreas with malignancy. 17 patients developed mental and psychological stress after suffering from the disease, but the patients' recognition of the disease improved significantly after treatment. Therefore, even for benign diseases, we should also need to fully explain that to the patients, and comfort the patients to reduce their psychological pressure.

In addition, we found some problems during follow-up. Even though heterotopic pancreas is a benign tumor, 3 patients accepted endoscopic resection in conservative treatment group, 9 patients developed recurrent (6 cases in the endoscopy group and 3 cases in the surgical group) and 3 patients developed malignant tumors ( 2 cases in the endoscopy group and 1 case in the surgical group). However, the cause of their malignant transformation is worth investigating. Therefore, endoscopic resection or surgical resection with regular follow-up is good alternatives for EP disease.

\section{Conclusions}

The clinical features of EP were not characteristic and it usually grows on the upper digestive tract. Endoscopic examination was a relatively good method to diagnose EP. The psychological stress caused by this disease was not many patients, and its attention was not high. Endoscopic therapy should be the first choice of treatment except for large tumors that must be treated surgically.

\section{Acknowledgements}

Thanks to all the people who have contributed to this research.

Informed consents were obtained from all patients for their inclusion in the study.

\section{Disclosure of conflict of interest}

None.

\section{References}

1. Elfving G, Hastbacka J. Pancreatic heterotopia and its clinical importance. Acta Chir Scand. 1965;130: 593-602.

2. Chandan VS, Wang W. Pancreatic heterotopia in the gastric antrum. Arch Pathol Lab Med. 2004;128: 111-112.

3. de Kok BM, de Korte FI, Perk LE, Terpstra V, Mieog JSD, Zijta FM. Acute clinical manifestation of mesenteric heterotopic pancreatitis: a pre- and postoperative confirmed case. Case Rep Gastrointest Med. 2018;2018: 5640379.

4. Qizilbash AH. Acute pancreatitis occurring in heterotopic pancreatic tissue in the gallbladder. Can J Surg. 1976;19: 413414.

5. Yang B, Valluru B, Guo YR, Cui C, Zhang P, Duan W. Significance of imaging findings in the diagnosis of heterotopic spleen-an intrapancreatic accessory spleen (IPAS): Case report. Medicine (Baltimore). 2017;96: e9040.

6. Lai EC, Tompkins RK. Heterotopic pancreas. Review of a 26 year experience. Am J Surg. 1986;151: 697-700.

7. Payeras G, Castellon C, De Jaime J, Barranco R, Calvache A, Castro P. Heterotopic pancreas: a difficult diagnosis. Endoscopy 2010;42 Suppl 2: E121.

8. Rösch T, Kapfer B, Will U, Baronius W, Strobel M, Lorenz R, Ulm K; German EUS Club. Endoscopic ultrasonography. Accuracy of endoscopic ultrasonography in upper gastrointestinal submucosal lesions: a prospective multicenter study. Scand J Gastroenterol. 2002;37: 856-862.

9. Changchien $\mathrm{CS}$, Hsiaw $\mathrm{CM}, \mathrm{Hu}$ TH. Endoscopic ultrasonographic classification of gastric aberrant pancreas. Chang Gung Med J. 2000;23: 600-607.

10. Besemann EF, Auerbach SH, Wolfe WW. The importance of roentgenologic diagnosis of aberrant pancreatic tissue in the gastrointestinal tract. Am J Roentgenol Radium Ther Nucl Med. 1969:107: 71-76 
11. Nelson RS, Scott NM Jr. Heterotopic pancreatic tissue in the stomach; gastroscopic features. Gastroenterology. 1958;34: 452-459.

12. Galvez-Valdovinos R, Mendoza-Rodriguez A, CoronadoPerez JH, Santillan EM, Funes-Rodriguez F. Laparoscopic treatment of heterotopic pancreas in the prepyloric region. J Minim Access Surg. 2006;2: 224-226.

13. Ryu DY, Kim GH, Park DY, Lee BE, Cheong JH, Kim DU, Woo HY, Heo J, Song GA. Endoscopic removal of gastric ectopic pancreas: an initial experience with endoscopic submucosal dissection. World J Gastroenterol. 2010;16: 4589-4593.

14. Papaziogas B, Koutelidakis I, Tsiaousis P, Panagiotopoulou K, Paraskevas G, Argiriadou H, Atmatzidis S, Atmatzidis $\mathrm{K}$. Carcinoma developing in ectopic pancreatic tissue in the stomach: a case report. Cases J. 2008;1: 249.

15. Trifan A, Tarcoveanu E, Danciu M, Hutanasu C, Cojocariu C, Stanciu C. Gastric heterotopic pancreas: an unusual case and review of the literature. J Gastrointestin Liver Dis. 2012;21: 209-212.

16. Tanaka K, Tsunoda $\mathrm{T}$, Eto $\mathrm{T}$, Yamada M, Tajima Y, Shimogama H, Yamaguchi T, Matsuo S, Izawa K. Diagnosis and management of heterotopic pancreas. Int Surg. 1993;78: 32-35.

17. Makarewicz W, Bobowicz M, Dubowik M, Kosinski A, Jastrzebski T, Jaskiewicz J. Endoscopic submucosal dissection of gastric ectopic pancreas. Wideochir Inne Tech Maloinwazyjne. 2013;8: 249-252.
18. Kopczynska M, Mokros L, Pietras T, Malecka-Panas E. Quality of life and depression in patients with irritable bowel syndrome. Prz Gastroenterol. 2018;13: 102-108.

19. Koukourakis IM, Perente Memet MS, Kouroupi M, Simopoulos K. Ectopic pancreatic tissue adherent to the external gallbladder wall. Case Rep Gastroenterol. 2018;12: 170-175.

20. Christodoulidis G, Zacharoulis D, Barbanis S, Katsogridakis E, Hatzitheofilou K. Heterotopic pancreas in the stomach: a case report and literature review. World $J$ Gastroenterol. 2007;13: 6098-6100.

21. Weppner JL, Wilson MR, Ricca R, Lucha PA Jr. Heterotopic pancreatic tissue obstructing the gallbladder neck: a case report. JOP. 2009; 10: 532-534.

22. Zarand A, Bajtai A, Baranyai Z, Dede K, Jakab F. Inflammation of ectopic pancreatic tissue in a Meckel's diverticulum causing acute abdominal symptoms: a case report and review of the literature. Int J Surg Pathol. 2011;19: 359-363.

23. Flores A, Papafragkakis C, Uberoi AS, Thaiudom S, Bhutani MS. EUS of an atypical ectopic pancreas. Endosc Ultrasound. 2018;7: 216-217.

24. Attwell A, Sams S, Fukami N. Diagnosis of ectopic pancreas by endoscopic ultrasound with fine-needle aspiration. World $J$ Gastroenterol. 2015;21: 2367-2373.

25. Agale SV, Agale VG, Zode RR, Grover S, Joshi S. Heterotopic pancreas involving stomach and duodenum. $J$ Assoc Physicians India. 2009;57: 653-654.

\footnotetext{
*Correspondence: Yongshun Gao, Department of Gastrointestinal Surgery, The First Affiliated Hospital of Zhengzhou University, Zhengzhou 450052, Henan, China, E-mail: 910491705@qq.com

Rec: Jul 03, 2019; Acc: Jul 23, 2019; Pub: May 28, 2019

Int Clin Med Therp. 2018;1(1):3

DOI: gsl.icmt.2019.00003

Copyright $(C 2019$ The Author(s). This is an open-access article distributed under the terms of the Creative Commons Attribution 4.0 International License (CCBY).
}

Int Clin Med Therp. 2019;1(1):3 